\title{
Interface shear strength of polypropylene pipeline coatings and granular materials at low stress level
}

\author{
Lawrence $W$ de Leeuw ${ }^{1 *}$, Andrea Diambra ${ }^{1}$, Matt $S$ Dietz ${ }^{1}$, George Mylonakis ${ }^{1}$, and Henry Milewski ${ }^{2}$ \\ ${ }^{1}$ School of Civil, Aerospace and Mechanical Engineering, University of Bristol, Bristol, UK \\ ${ }^{2}$ TechnipFMC, Westhill, UK
}

\begin{abstract}
A range of sands were tested in direct and interface shear at very low stresses to determine the interface shear strength of polypropylene pipeline coating counterfaces and to evaluate interface efficiency. Polypropylene has a wide range of applications as a coating material in the offshore environment, so quantification of interfacial strength is an important component for geotechnical design. Direct shear tests show classic peak-postpeak stress-displacement and stress-dilatancy behaviour whereas interface tests show an elastic, perfectly plastic type behaviour for both loose and dense samples with no appreciable volumetric response. Interface efficiencies generally range between 0.3 and 0.7 dependent on both grain size and stress level. Normalised roughness is used to relate the surface roughness to the grain size and shows that the greater interface strength with smaller grained sands can be explained by their greater effective roughness. The relationship between stress ratio and normalised roughness for sand-polypropylene resembles established relationships for sand-steel interfaces.
\end{abstract}

\section{Introduction}

Subsea hydrocarbon pipelines and electrical cables are laid either directly on the seafloor or buried in shallow trenches to protect them from adverse hydrodynamic loading or damage from fishing gear. Protective coatings are applied to protect the pipeline and also provide protection from corrosion and abrasion. A widely used material for coatings is polypropylene. Polypropylene coatings are applied to electrical cables in the form of a dense yarn sometimes mixed also with bitumen. A common technique for pipeline coating is extrusion of polypropylene into a strip to wrap around the pipe to form a relatively smooth coherent surface and this type of application is the focus of this research.

On dynamic seabeds comprising loose sands, loads transferred from pipe to soil in response to thermal expansion and contraction causing buckling or pipeline walking are restrained principally by the strength of the polypropylene-soil interface. Therefore, correct quantification of the interface friction coefficient and impact on interface is key to ensuring the structural integrity of the infrastructure. Numerous researchers have explored the interface strength of polymers and sands including M- and HDPE, PVC, Epoxy, plexiglass [1-4 among others] and it appears customary to link the interface strength to the hardness of plastic polymers [4]. The effect of soil gradation on interface strength of polypropylene has also previously been explored [5].
The present work expands the previous research by investigating the role of grain size and stress level on interface strength with reference to surface roughness relative to grain size. The work used the same polypropylene surfaces as in de Leeuw et al. [5].

Normal stress levels of between $2.5 \mathrm{kPa}$ and $35 \mathrm{kPa}$ were selected for this research to cover the range relevant to both subsea and onshore pipelines and cables. The upper part of the range followed the example of O'Rourke et al. [4] whereas the very low stresses for subsea conditions were after White and Cathie [6]. Testing was undertaken using the Winged Direct Shear Apparatus developed at University of Bristol [7] on three known soils and one dredged soil, of varying $D_{50}$. It is hoped this research will provide some useful data for design of offshore pipelines and cables.

\section{Materials}

\subsection{Granular materials}

Four different granular soils were used in this research, three sands well known in the literature and one dredged from the North Sea and prepared in the laboratory for this work. Leighton Buzzard 14-25 sand (also known as Fraction B) (LBB), Hostun Sand (HS), and Redhill Sand (RH) were the known sands. Lowestoft Gravel (LG) was the coarsest test sand and was dredged from the North Sea off the Suffolk coast near Lowestoft and was bulked out with crushed quartz-rich aggregate. The particle size

\footnotetext{
${ }^{*}$ Corresponding author: lawrence.deleeuw@bristol.ac.uk
} 
distribution for each test sand is presented in Figure 1 and the main properties are provided in Table 1 .

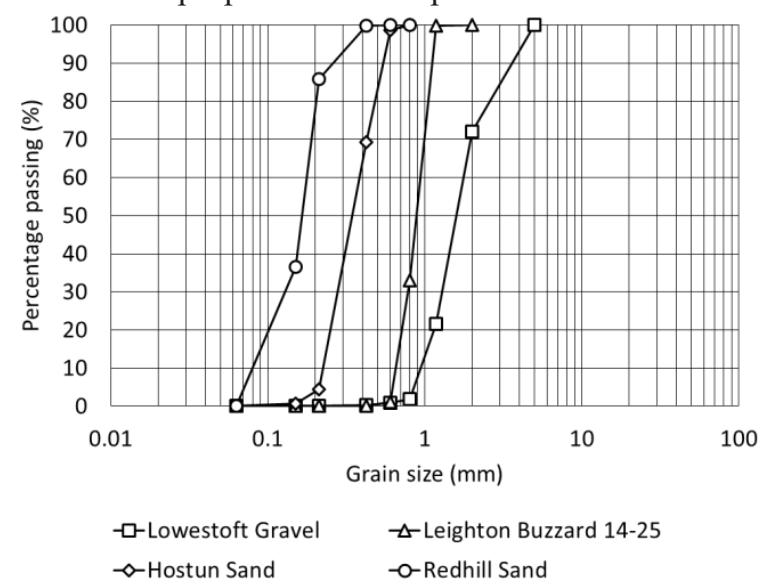

Fig. 1. Particle size distribution for the four granular materials

Table 1 Main properties for the four granular materials

\begin{tabular}{lcccc}
\hline & $\begin{array}{c}\text { Lowestoft } \\
\text { Gravel }\end{array}$ & $\begin{array}{c}\text { Leighton } \\
\text { Buzzard } \\
\mathbf{1 4 - 2 5}\end{array}$ & $\begin{array}{c}\text { Hostun } \\
\text { Sand }\end{array}$ & $\begin{array}{c}\text { Redhill } \\
\text { Sand }\end{array}$ \\
\hline$e_{\max }$ & 0.94 & 0.84 & 1.00 & 1.04 \\
$e_{\min }$ & 0.55 & 0.53 & 0.62 & 0.61 \\
$D_{50}(\mathrm{~mm})$ & 1.59 & 0.88 & 0.35 & 0.17 \\
$C_{u}$ & 1.88 & 1.44 & 1.71 & 2.22 \\
$C_{g}$ & 1.00 & 1.00 & 0.90 & 1.17 \\
\hline
\end{tabular}

\subsection{Polypropylene surfaces}

Four specimens of polypropylene coating were used for this testing campaign which were supplied and prepared by TechnipFMC having been removed from an already manufactured steel pipe. The coating was removed by heating to soften the bonding resin and then peeling the coating from the pipe. The resulting samples were flattened under $20 \mathrm{~kg}$ masses at $160^{\circ} \mathrm{C}$ and allowed to cool to ambient temperature before being trimmed to the appropriate size for the shear box. Care was taken to ensure the test specimens did not have any seams running across their faces; seams are an inevitable result of the manufacturing processes where extruded polypropylene is wrapped around the pipe. In addition to avoiding specimens with seams, surfaces which had the most uniform surface free from large variations in surface texture or form were selected. Such precautions, although not realistic, minimised uncontrolled variables.

Hardness is a key property of polymers and is typically measured with a durometer to give a Shore D hardness value. In O'Rourke et al. [4] the range of hardness of surface specimens was between 30 and 90. The polypropylene specimens used in this research had a Shore D hardness of approximately 70.

\section{Methodology}

\subsection{Testing apparatus}

Direct and interface shear testing was carried out using the Winged Direct Shear Apparatus (WDSA) developed by Lings and Dietz [7]. It is a modification of the traditional Direct Shear Apparatus (DSA) where instead of the shear load being applied directly from the front of the shear box, it is instead transferred through a pair of wings via ball races. This arrangement improves the articulation of the force transmission system so the loads acting on the specimen are more reliably quantified. The load from the shear box to load cell is now measured closer to the centre of the shear box and the ball races allow free vertical movement of the top cap so dilation can occur unimpeded. During soil tests the bottom plate was secured inside the shear box lower frame by an arrangement of fixing screws. Similarly, the load pad was secured within the upper frame as recommended by Jewell and Wroth [8] to create a symmetrical test configuration which acts to reduce upper frame rotation. The gap between the upper and lower frame was pre-set before sample preparation to at least $5 \cdot D_{50}$ for the coarser test sands, or at least $4 \mathrm{~mm}$ for the finer test sands. Setting such a gap size has been empirically shown to eliminate the need for an area correction that would otherwise be needed to correct for the reducing sample area in soil tests as the frame translates. [7]. In interface tests area corrections become redundant regardless of gap size due to the oversize interface in relation to the shearing area.

For interface tests the upper frame was replaced with an aluminium load pad to which the surfaces were attached with a series of perimeteral countersunk bolts such that the resultant surface was flat. Linear Variable Differential Transformers (LVDT) were used to measure the horizontal and vertical displacement. Vertical displacement was measured centrally to record dilation or contraction. Two further LVDTs were placed off-centre along the axis of horizontal displacement to measure any rotation of the top cap about the centre line perpendicular to the shearing direction. An S-type 500N load cell was used to measure the force required to restrain the upper half during lower half translation. In both direct shear and interface tests, $1 \mathrm{~mm}$ thick rubber strips were placed around the inside edge of the frames to form a curtain to prevent sample loss through the gap during shearing.

\subsection{Sample fabrication}

Direct shear samples were deposited into the shear box frames by the dry deposition pluviation method described by Miura et al. [9] to achieve the lowest possible density. Sand was poured through a funnel into the shear box ensuring zero drop-height and the resulting mound then gently flattened to create a level upper surface. If the sample density was lower than planned, the sample was gently vibrated through an aluminium plate to encourage settlement to the target density. Dense samples were prepared in a similar way but using the precise mass of required soil as calculated prior to pouring using the known dimensions of the box and soil properties.

Interface tests were prepared upside down, i.e. the sand was poured directly onto the upturned counterface to ensure good contact across the shearing surface. As 
previously, the shear box was vibrated to achieve the target sample density and an aluminium plate secured across the flattened upper surface. The whole assembly was then inverted in one smooth movement and seated into the shear box carriage for testing.

\subsection{Test procedure}

A total of 40 direct shear and 40 interface shear tests were carried out using the four test sands at: i) loose and dense nominal densities (30\% and $70 \%$ respectively) and ii) nominal normal stresses of $2.5,5,10,20$, and $35 \mathrm{kPa}$. The shear rate was approximately $0.75 \mathrm{~mm} /$ minute and tests were carried out submerged with the water at ambient laboratory temperatures of approximately $21^{\circ} \mathrm{C}$. For interface tests, one polypropylene counterface was used for all tests of the same sand type. To minimise the impact of roughening the surface through formation of striations, testing was carried out in order of increasing normal stress and loose before dense.

\subsection{Surface roughness and topography}

Surface specimens were imaged using an Alicona InfiniteFocus digital microscope which allows noncontact optical 3D measurement of surfaces using focus variation to determine the topography. Figure 2 presents a typical processed 3D surface output from the Alicona with an artificial colour scheme applied to differentiate topography relative to the centre line. The $2 \mathrm{D}$ surface trace is included from which roughness parameters were extracted.

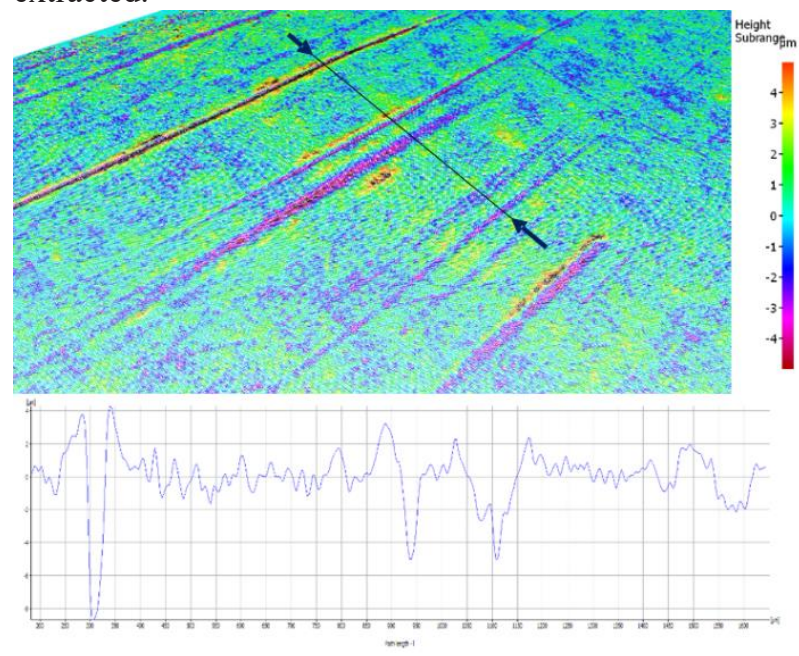

Fig. 2. Typical processed 3D surface image generated by the Alicona InfiniteFocus and 2D surface profile extracted from it.

The selected magnification of $10 x$ allowed a resolution down to $250 \mathrm{~nm}$ and for the purposes of this work an area of $100 \mathrm{~mm} 2$ was selected for measurement. The software generates a 3D surface in $\mathrm{X}, \mathrm{Y}$, and $\mathrm{Z}$ from which profiles could be extracted to determine roughness parameters, including $\mathrm{Ra}$ - the arithmetic mean deviation of the profile from its centre line. The averaged roughness from multiple traces per specimen ranged from 0.72 to 1.07 microns.

\section{Results}

\subsection{Direct shear tests}

Direct shear stress against displacement and vertical against horizontal displacement plots for Leighton Buzzard 14-25 as a typical example are presented in Figure 3 showing classical peak-postpeak and stress dilatancy behaviour.

Leighton Buzzard stress-displacement

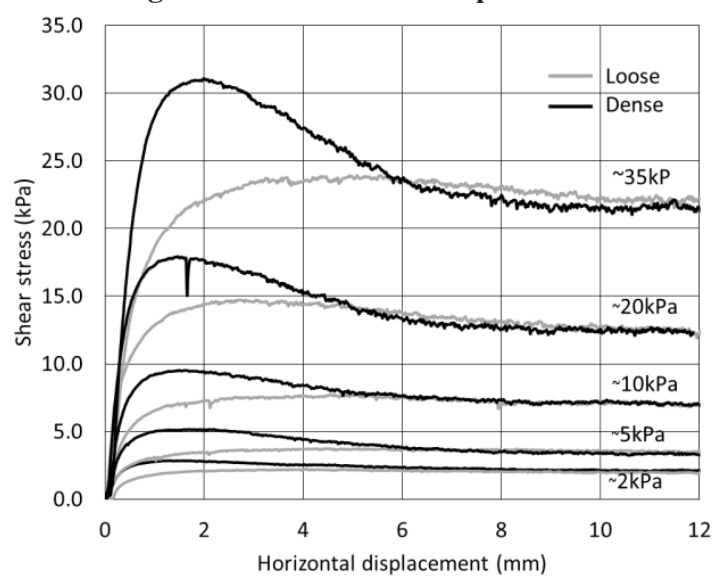

Leighton Buzzard vertical-horizontal displacement

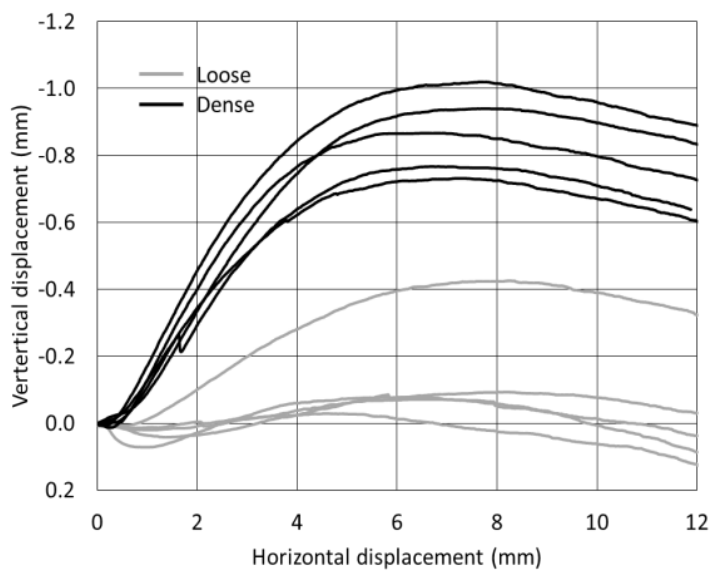

Fig. 3. Typical stress-displacement and horizontal displacement plots for direct shear using Leighton Buzzard 14-25 with dense tests in black and loose tests in grey.

Direct shear results are most helpfully discussed in terms of stress ratio; the ratio between peak or ultimate shear stress and normal confining stress (Figure 4).

\section{Lowestoft Gravel}

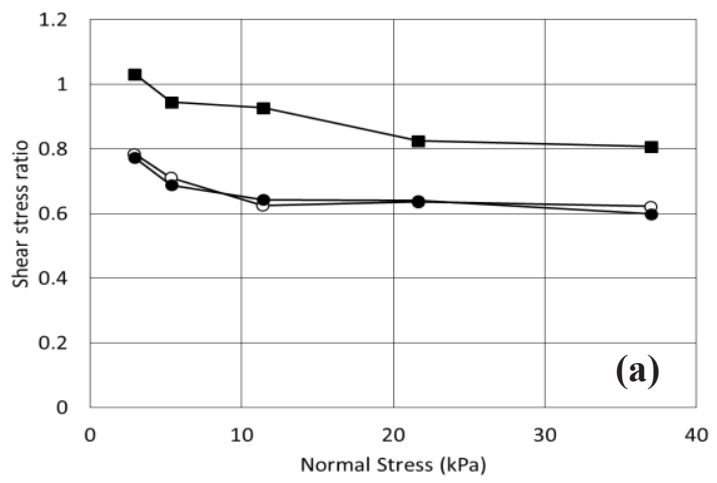



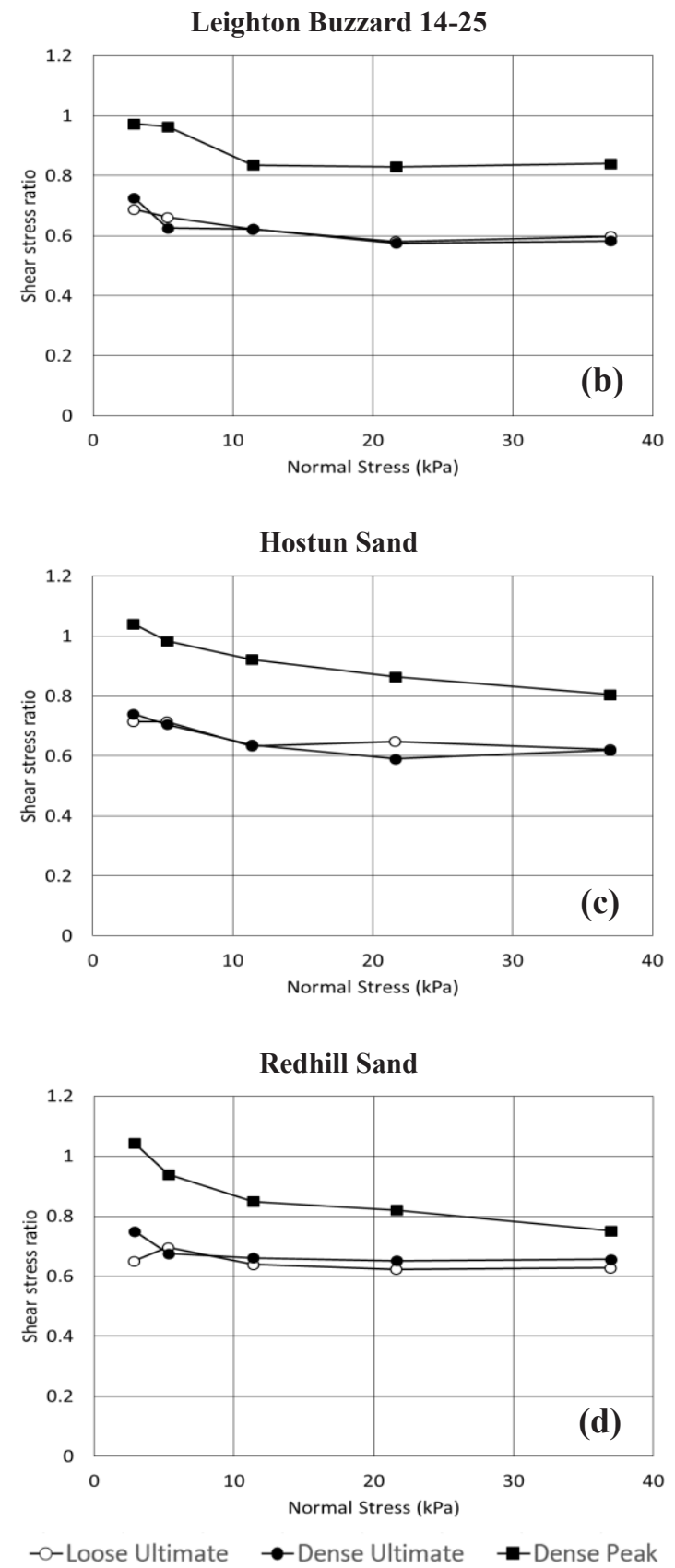

Fig. 4. Stress ratio against normal stress for direct shear tests: (a) Lowestoft gravel, (b) Leighton Buzzard 14-25, (c) Hostun Sand, (d) Redhill Sand.

There is good agreement in ultimate strengths between the dense and loose configuration tests and the peak envelope is clearly differentiated indicating the expected peak-postpeak behaviour. The failure envelopes for peak and postpeak are nonlinear for all test sands and exhibit an enhancement to shear strength at very low stresses in the order of 0.1 to 0.3 stress ratio.

\subsection{Interface shear tests}

Interface shear stress against horizontal displacement and vertical against horizontal displacement plots for Leighton Buzzard 14-25 as a typical example in dense configuration are presented in Figure 5 showing a very different behaviour compared to the direct shear results.

\section{Leighton Buzzard 14-25 stress-displacement}

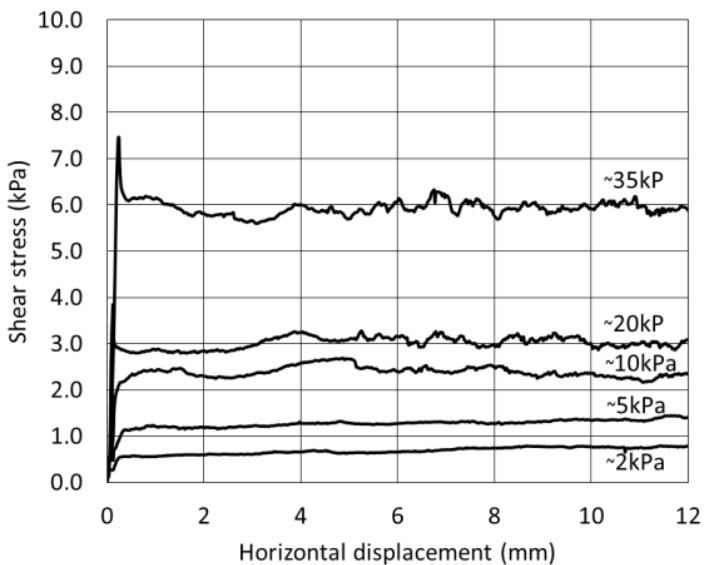

Leighton Buzzard vertical-horizontal displacement

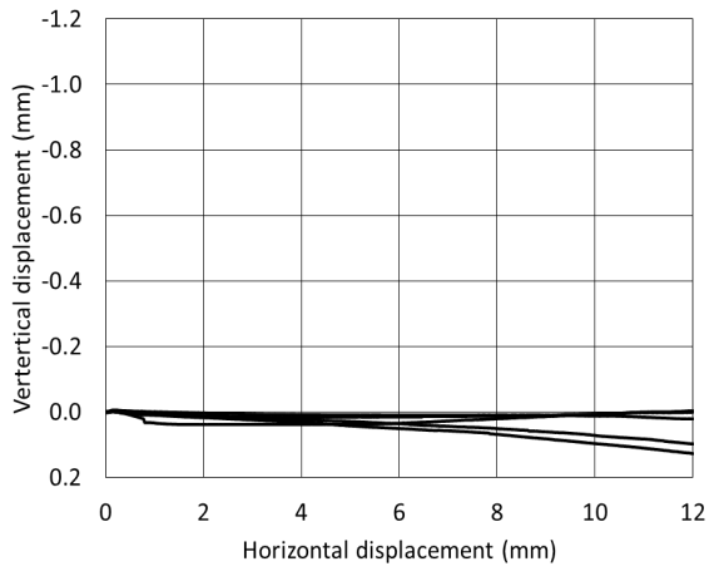

Fig. 5. Typical stress-displacement and horizontal displacement plots for dense interface shear using Leighton Buzzard 14-25.

In contrast to direct shear tests, polypropylene interface tests do not exhibit peak-postpeak behaviour and there is no stress-dilatancy associated with shearing. During shearing the shear stress increases rapidly to a plateau and then remains largely stable through the duration of the test providing only an ultimate shear stress in both loose and dense configurations. There is very little appreciable volumetric response associated with interface shearing. Figure 6 shows interface stress ratio against normal stress.

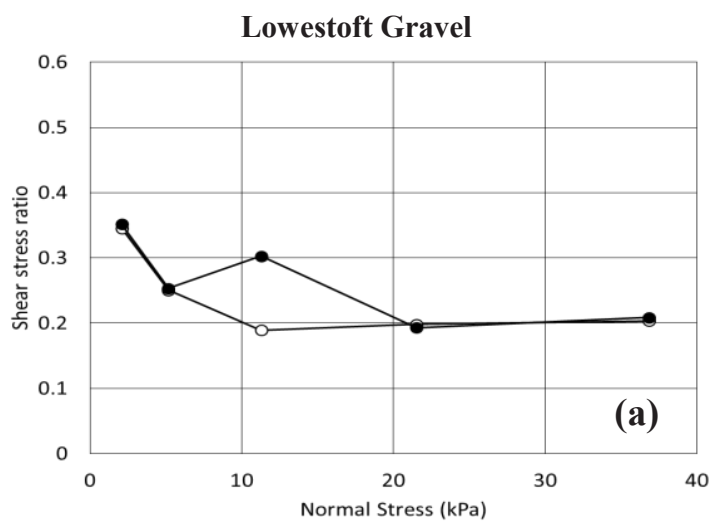




\section{Leighton Buzzard 14-25}

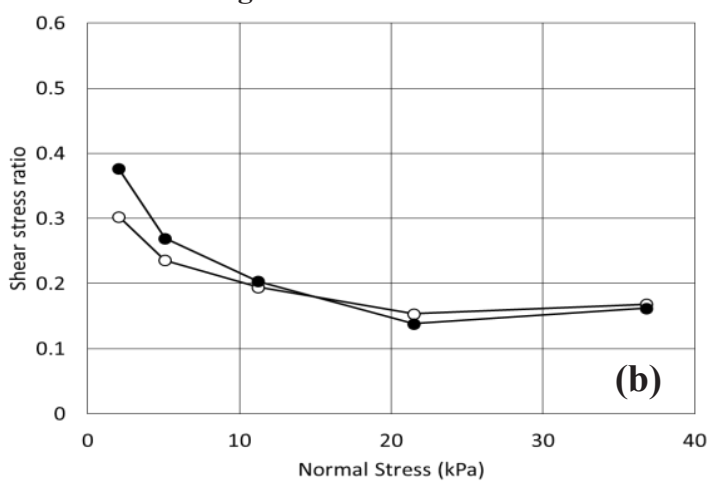

Hostun Sand

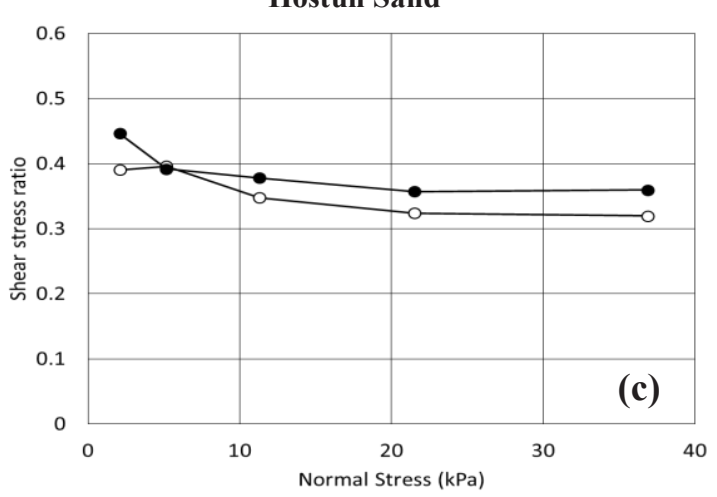

Redhill Sand

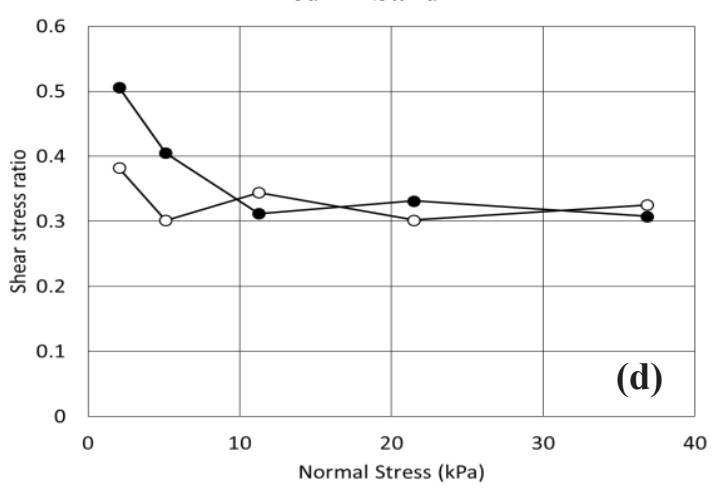

-O-Loose Ultimate $\rightarrow$-Dense Ultimate

Fig. 6. Stress ratio against normal stress for interface shear tests: (a) Lowestoft gravel, (b) Leighton Buzzard 14-25, (c) Hostun Sand, (d) Redhill Sand.

In interface tests there is a subtle tendency for dense tests to mobilise a slightly greater shear strength compared to their loose test counterparts. Since there is little appreciable volumetric response it may be conjectured that the strength increase is related to an increase in the number of contacts between the soil particles and the surface [10]. Lower normal stress may cause fewer individual grains to be pressed onto the surface resulting in the normal load being distributed over fewer unique grains contacting the surface. Such a scenario would mean greater contact stresses at each contact point leading to an enhancement in shear resistance at those points. Strength enhancements at low stress in both direct and interface shear may be explained in this way.

\subsection{Interface efficiency}

The interface efficiency, defined as the ratio between the interface ultimate stress ratio and the soil ultimate stress ratio, is a useful measure for determining interface strengths from soil test data. O'Rourke [4] compares the interface efficiency with the Shore D hardness which suggests an interface efficiency of 0.53 for the present materials. In the present study there is large variation in interface efficiency and a clear grouping according to grain size (Figure 7). Smaller grained sands have greater interface efficiency of approximately 0.5-0.6, compared to larger grained sands which achieve only $0.3-0.4$. In both cases the strength enhancement at very low stress still plays a role improving interface efficiency.
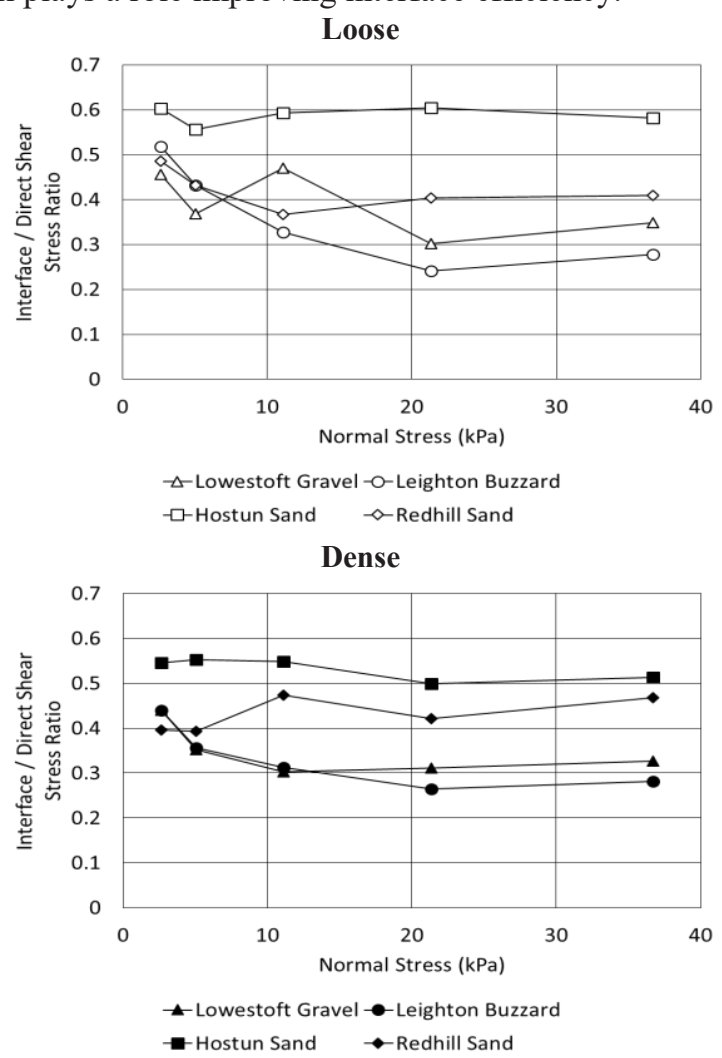

Fig. 7. Ratios between the ultimate strengths obtained in the direct shear and the interface shear tests against applied vertical confinement stress

\section{Discussion}

The difference in interface efficiency between the larger and smaller grained test sands suggests that the hardness of the interface is not the only variable governing the interface strength. The observed interface efficiency trends can be explained by the roughness of the surface and its relationship with the grain size. Smaller grains will experience a greater roughness on a given topography than larger grains on the same surface. To evaluate this effect, the term normalised roughness [11] is used which relates grain size to the roughness parameter. Here normalised roughness is defined as $\mathrm{R}_{n o r m}=\mathrm{R}_{a} / D_{50}$ where $\mathrm{R}_{a}$ is the arithmetic mean roughness as measured by noncontact profilometry using an Alicona InfiniteFocus noncontact profilometer. For larger grained test sands, the 
$\mathrm{R}_{\text {norm }}$ is 0.00049 and 0.00082 for Lowestoft Gravel and Leighton Buzzard 14-25 respectively. For Hostun Sand and Redhill Sand the $\mathrm{R}_{\text {norm }}$ values are 0.00243 and 0.00632 respectively. Examination of Figure 5 confirms that generally the order of increasing $\mathrm{R}_{\text {norm }}$ is reflected in the order of increasing interface efficiency except for Hostun Sand and Redhill Sand where the order is reversed. The influence of grain angularity has not been studied and Hostun Sand is markedly more angular than Redhill Sand which may explain the discrepancy.

In Figure 8 ultimate stress ratios at approximately $20 \mathrm{kPa}$ normal stress are plotted against normalised roughness for the four test sands. The black lines represent the trend identified in Dietz and Lings [12] for the relationship between ultimate stress ratio and normalised roughness for sand-steel interfaces at $25 \mathrm{kPa}$. It is intriguing to note that despite the obvious differences in hardness and material properties between polypropylene and steel, their interfacial responses resemble one another in terms of the relationship between stress ratio and roughness normalised to the grain size.

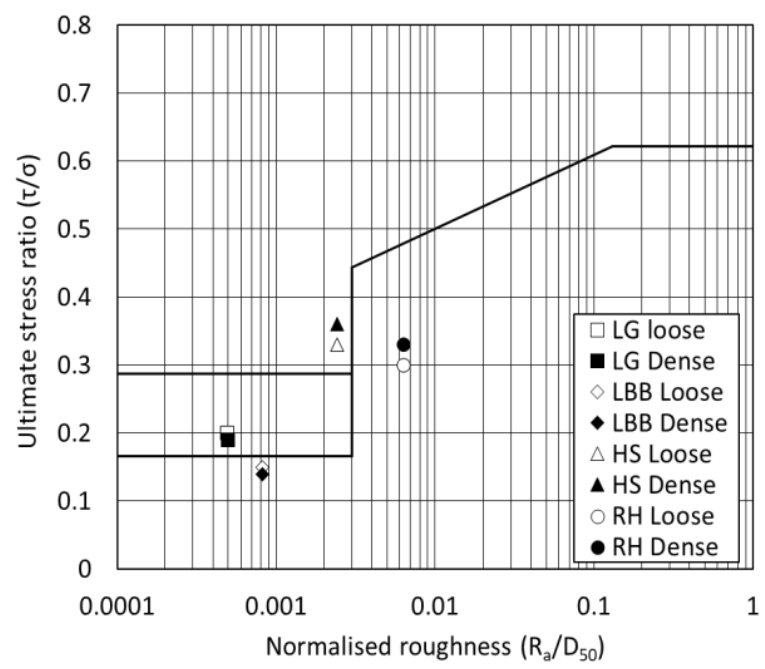

Fig. 8. Normalised roughness of surfaces against ultimate stress ratio for test sands and polypropylene surfaces. Trendline for sand-steel interfaces after Lings and Dietz at $25 \mathrm{kPa}$ [12].

\section{Conclusions}

The results of an experimental program aiming to determine the interface strength between polypropylene pipeline coating and different granular materials have been presented. The results have shown that the hardness of the surface is not the only parameter governing the interface friction. Despite polypropylene coatings normally considered to be smooth surfaces, the interface strength varies with soil type and appears to be governed also by the value of its roughness normalised to grain size. Interface strength and efficiency appears to be strongly influenced by the grain size of the test sand where smaller grain sizes effect a greater interface strength. The effect of grain angularity has not been studied but is also likely to have an impact on the interface shear strength. The relationship between ultimate shear stress and normalised roughness for sand-polypropylene interfaces echoes well established relationships for sand-steel interfaces at lower levels of normalised roughness. Investigating the rest of the trend line with reference to soil-polypropylene interfaces is the focus of future work.

The authors wish to thank TechnipFMC for commissioning and specifying the scope of this research and acknowledge the technical collaboration on this project.

\section{References}

1. T.S. Ingold. Reinforced Earth. Eds: Thomas Telford, London

2. S.K. Saxena, Y.T. Wong. Proc. Int. Con. Geomembranes, 187-190 (1984)

3. D. Negussey, W.K.D. Wijewickreme, Y.P. Vaid. Can. Geotech. J., 26, 165-169 (1989)

4. T.D. O'Rourke, S.J. Druschel, A.N Netravali. J. Geotech. Eng., 116, 451-469 (1990)

5. L.W. de Leeuw, H. Milewski, G. Martin, M.S. Dietz, A. Diambra. In preparation (2019)

6. D.J. White, D.N. Cathie. Proc. $2^{\text {nd }}$ Int. Sym. Frontiers in Offshore Geotechnics.87-123 (2011)

7. M.L. Lings, M.S. Dietz. Geotechnique, 54, 245-256 (2004)

8. R.A. Jewell, C.P. Wroth. Geotechnique, 37, 53-68 (1987

9. K. Mirua, K. Maeda, S. Toki. Soils and Foundations, 37, 89-96 (1997)

10. J.E. Dove, J.D. Frost. J. Geotech. Geoenv. Eng., 125, 544-555 (1999)

11. M. Uesugi, H. Kishida. Soils and Foundations, 26, 139-149 (1986)

12. M.S. Dietz, M.L. Lings. J. Geotech. Geoevn. Eng., 132, 1474-148 (2006) 